\title{
Chronic Cigarette Smoking Alters Circulating Sex Hormones and Neuroactive Steroids in Premenopausal Women
}

\author{
M. DUŠKOVÁ ${ }^{1}$, K. ŠIMŮNKOVÁ ${ }^{1}$, M. HILL ${ }^{1,4}$, M. VELÍKOVÁ ${ }^{1}$, J. KUBÁTOVÁ ${ }^{1}$, \\ L. KANCHEVA ${ }^{1}$, H. KAZIHNITKOVÁ ${ }^{1}$, H. HRUŠKOVIČOVÁ ${ }^{1}$, H. POSPÍŠILOVÁ ${ }^{1}$, \\ B. RÁCZ ${ }^{1}$, M. SALÁTOVÁ ${ }^{1}$, V. CIRMANOVÁ ${ }^{1}$, E. KRÁLÍKOVÁ ${ }^{2,3}$, L. STÁRKA ${ }^{1}$, \\ A. PAŘÍZEK ${ }^{4}$
}

${ }^{1}$ Institute of Endocrinology, Prague, Czech Republic, ${ }^{2}$ Institute of Hygiene and Epidemiology, First Faculty of Medicine, Charles University, Prague, Czech Republic, ${ }^{3}$ Tobacco Dependence Treatment Centre, Third Medical Department - Department of Metabolism and Endocrinology, First Faculty of Medicine, Charles University, Prague, Czech Republic, ${ }^{4}$ Department of Obstetrics and Gynecology of the First Faculty of Medicine, Charles University, Prague, Czech Republic

Received February 18, 2011

Accepted October 27, 2011

On-line December 20, 2011

\section{Summary}

Chronic smoking alters the circulating levels of sex hormones and possibly also the neuroactive steroids. However, the data available is limited. Therefore, a broad spectrum of free and conjugated steroids and related substances was quantified by GC-MS and RIA in premenopausal smokers and in age-matched

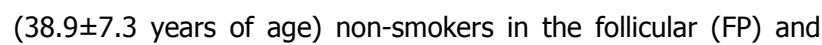
luteal phases (LP) of menstrual cycle (10 non-smokers and 10 smokers, in the FP, and 10 non-smokers and 8 smokers in the LP). Smokers in both phases of the menstrual cycle showed higher levels of conjugated 17-hydroxypregnenolone, 5a-dihydroprogesterone, conjugated isopregnanolone, conjugated 5a-pregnane-3 $\beta, 20 a-d i o l$, conjugated androstenediol, androstenedione, testosterone, free testosterone, conjugated $5 a$-androstane-3a/ $\beta, 17 \beta$-diols, and higher free testosterone index. In the FP, the smokers exhibited higher levels of conjugated pregnenolone, progesterone, conjugated pregnanolone, lutropin, and a higher lutropin/follitropin ratio, but lower levels of cortisol, allopregnanolone, and pregnanolone. In the LP, the smokers exhibited higher levels of free and conjugated 20a-dihydropregnenolone, free and conjugated dehydroepiandrosterone, free androstenediol, 5a-dihydrotestosterone, free and conjugated androsterone, free and conjugated epiandrosterone, free and conjugated etiocholanolone, 7a/ $\beta$-hydroxy-dehydroepiandrosterone isomers, and follitropin but lower levels of estradiol and sex hormone binding globulin (SHBG) and lower values of the lutropin/follitropin ratio. In conclusion, chronic cigarette smoking augments serum androgens and their $5 a / \beta$-reduced metabolites (including GABAergic substances) but suppresses the levels of estradiol in the LP and SHBG and may induce hyperandrogenism in female smokers. The female smokers had pronouncedly increased serum progestogens but paradoxically suppressed levels of their GABA-ergic metabolites. Further investigation is needed concerning these effects.

\section{Key words}

Smoking • Menstrual cycle • Luteal phase $\bullet$ Follicular phase • Sex hormones • Neuroactive steroids

\section{Corresponding author}

Antonín Pařizek, Department of Obstetrics and Gynecology of the First Faculty of Medicine and General Teaching Hospital, Apolinářská 18, 12851 Prague 2, CZ 116 94, Czech Republic. Fax: +420224922 545. E-mail: parizek@porodnice.cz

\section{Introduction}

Cigarette smoking is one of the most serious substance abuse problems. A variety of human and animal studies have shown that nicotine can induce changes in female hormonal balance (Kapoor and Jones 2005, Tutka 2001, Tziomalos and Charsoulis 2004, Windham et al. 2005). Besides for the common 
reproductive functions in women (Kapoor and Jones 2005, Windham et al. 2005), such as the menstrual cycle, fertility, gravidity and the health of the fetus, chronic smoking may also influence the activities of the pituitaryadrenal axis and central nervous system (Rohleder and Kirschbaum 2006). The effects of chronic smoking on cognition (Durazzo and Meyerhoff 2007, Hill et al. 2003, Richards et al. 2003, Sabia et al. 2008), mood (BertoneJohnson et al. 2008), and severity of drug addiction (Sofuoglu et al. 2009, Sofuoglu et al. 2007) have been reported. It is generally accepted that the chemicals in tobacco smoke alter endocrine function in women, perhaps at the level of the ovaries, which in turn influences the release of pituitary hormones. More than 30 carcinogenic chemicals, including nicotine, cotinine cadmium, and polyaromatic hydrocarbons, are present in tobacco smoke; many of them are fat-soluble and resistant to metabolism (Mlynarcikova et al. 2005, Mukherjee et al. 2006, Shiverick and Salafia 1999). This endocrine disruption likely contributes to reported associations of smoking with adverse reproductive outcomes, including menstrual dysfunction (Windham et al. 1999), infertility, and earlier menopause. Studies on the effects of smoking on female sex hormones have concentrated mainly on estrogens and progesterone in the follicular phase of the menstrual cycle (Lucero et al. 2001, Zumoff et al. 1990).

Mood and well-being are strongly affected by neurotransmitters and corresponding receptors in brain structures. The effect of smoking on the concentration of gamma-aminobutyric acid (GABA) in the brain has been reported (Epperson et al. 2005). Short-term abstinence had no significant effect on cortical GABA concentrations in either men or women. There was, however, a significant effect of sex, diagnosis (smoker/non-smoker), and the menstrual cycle phase on cortical GABA levels. The female smokers experienced a significant reduction in cortical GABA levels during the follicular phase but no cyclicity in GABA levels across the menstrual cycle. Alternatively, cortical GABA levels were similar in smoking and nonsmoking men. The aforementioned data indicate possible alterations in the biosynthesis and/or catabolism of neuroactive steroids in premenopausal smokers. However, only little attention was paid to neurosteroids (known as potent modulators of type A GABA receptors $\left(\mathrm{GABA}_{\mathrm{A}}-\mathrm{r}\right)$ and NMDA receptors (NMDA-r)) in these subjects. Therefore, we attempted to establish whether the pattern of circulating neuroactive steroids, their precursors and metabolites
(Figures 1 and 2), differs between premenopausal smokers and age-matched non-smokers in the follicular (FP) and luteal phases (LP) of the menstrual cycle.

\section{Patients and Methods}

A broad spectrum of $\mathrm{C}_{19}$ and $\mathrm{C}_{21}$-steroid metabolites and related substances was determined by GC-MS and RIA in four groups of smokers and in agematched non-smokers in the follicular (FP) and luteal phases (LP) of the menstrual cycle. The first group consisted of premenopausal chronic smokers in the FP $(\mathrm{n}=10)$, while the second group involved the age- and phase of the menstrual cycle-matched non-smokers $(n=10)$. The third group contained premenopausal chronic smokers in the LP $(n=8)$ and the fourth group included the age and phase of the menstrual cycle-matched nonsmokers $(n=10)$. The patients were smokers who were interested in cessation and visited The Center for Tobacco Dependence, First Faculty of Medicine and General University Hospital, Prague. The controls had no history of smoking.

The study included women with regular menstrual cycles lasting 28 days. This inclusion criterion was fulfilled in both controls and patients. The blood in both groups was collected the $3^{\text {rd }}-5^{\text {th }}$ day of the menstrual cycle in the FP and the $22^{\text {nd }}-24^{\text {th }}$ day in the LP. The women, in whom the hormonal parameters did not accord with the phase of the menstrual cycle, were additionally excluded from the study. For the correct determination of the phase of the menstrual cycle, we have used the patient's self report and we also checked their serum hormonal levels. The ranges within the $3^{\text {rd }}$ and the $5^{\text {th }}$ day and within the $22^{\text {nd }}$ and $24^{\text {th }}$ day of the menstrual cycle were selected due to organizational reasons. In both patients and controls, we strived to complete the blood withdrawal as closest to the $3^{\text {rd }}$ and $22^{\text {nd }}$ days of the menstrual cycle as possible.

For ethical reasons, the design of the study does not allow sampling the same women in both cycles, even if the multiple cycles sampling in the same two groups (smokers vs. non-smokers) would be optimal and would increase the validity of our findings. Unfortunately, it was impossible to harmonize the patient's preference of the day, when the woman decided to cease smoking, with her menstrual cycle. Therefore, only those smokers who were within the aforementioned ranges for FP or LP on the beginning of the smoking cessation were included in the study. 


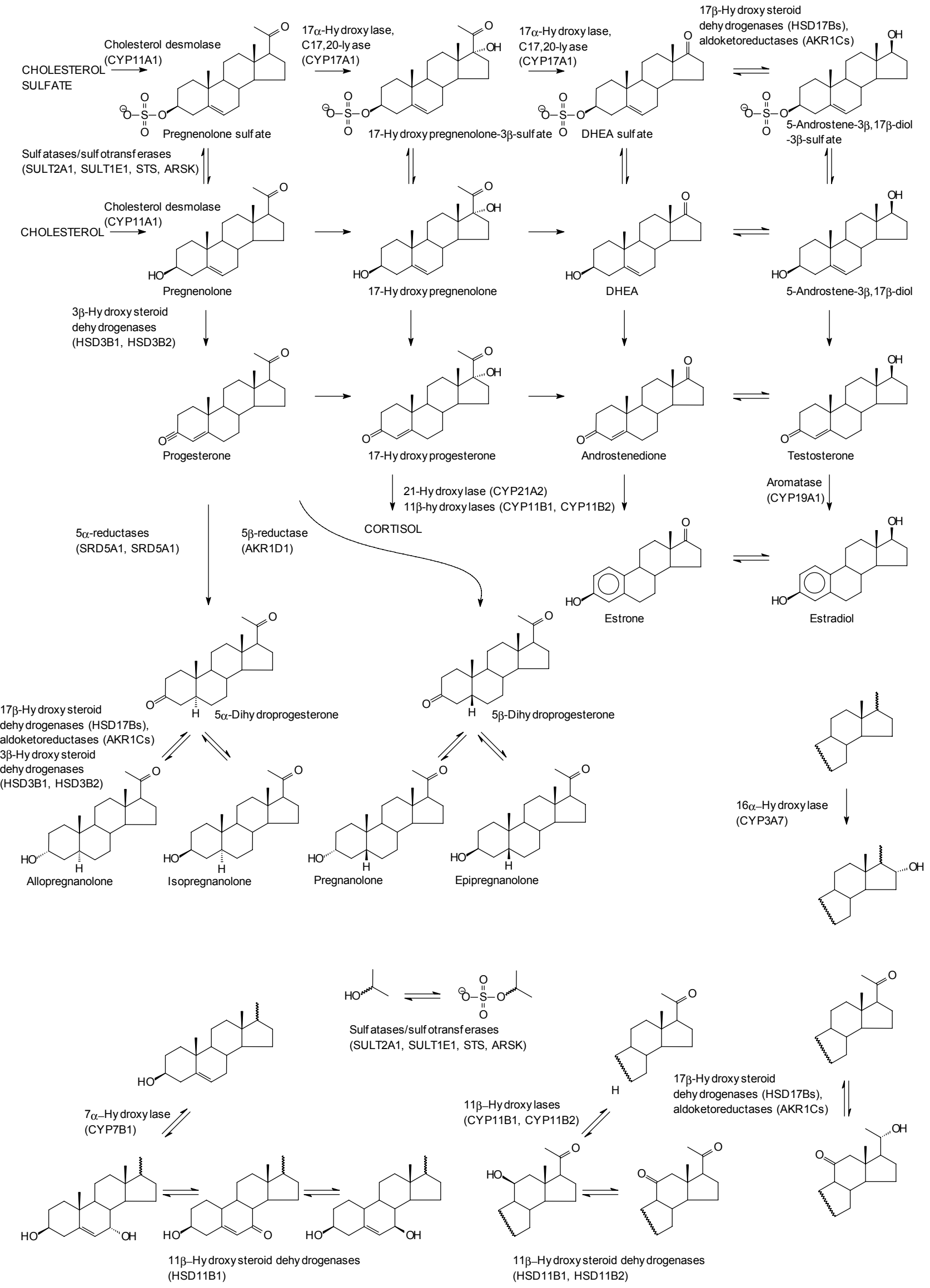

Fig. 1. Simplified scheme of steroidogenesis. 


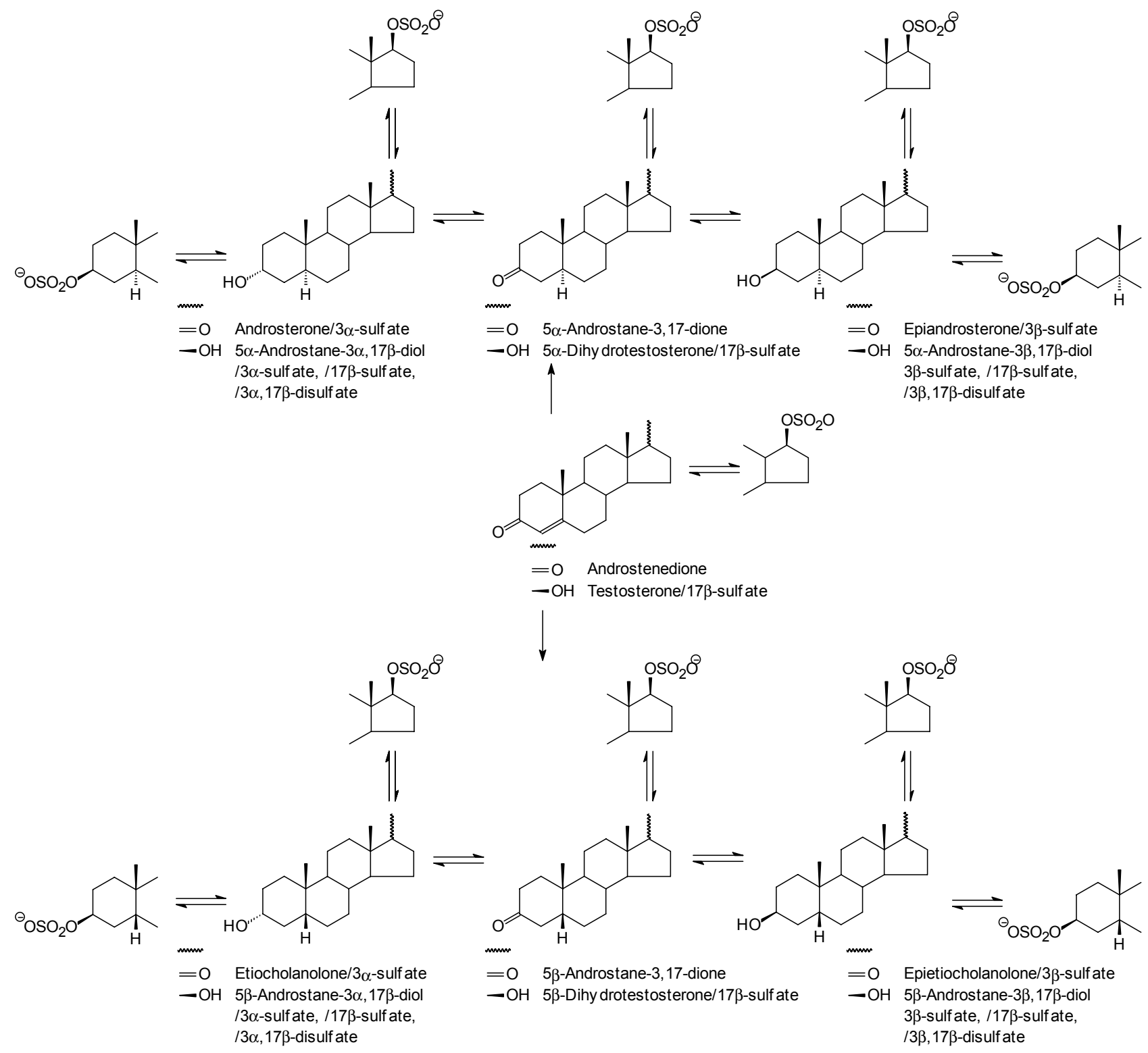

Fig. 2. Simplified scheme of the biosynthesis of $5 a / \beta$-reduced $C 19$ steroids.

Neither the control nor patients used hormonal contraception at least 6 months before the trial. They did not use anti-inflammatory drugs, antiepileptic drugs, antidepressants, or medication influencing the steroidogenesis. The women did not suffer from chronic disease or endocrinopathy. The age and BMI of the participants and the smoking behaviors of the smokers are illustrated in Table 1. The BMI of the controls and smokers did not differ significantly and was within the normal limit. The exclusion criteria for both groups were endocrine disease of any type, the use of hormonal contraception, and irregular menstruation.

A peripheral blood sample $(10 \mathrm{ml})$ was collected from the cubital vein, either in the FP or LP. The phase of the cycle was checked by the determination of circulating gonadotropins, estradiol, and progesterone. A progesterone serum level over $6 \mathrm{nmol} / \mathrm{l}$ was selected as the inclusion criterion for the LP (Young 1987). Cooled plastic tubes were used for blood sampling. The serum was obtained after centrifugation for 5 minutes at $2000 \mathrm{~g}$ at $4{ }^{\circ} \mathrm{C}$. The serum samples were stored at $-20{ }^{\circ} \mathrm{C}$ until analyzed.

The Ethics Committee of the Institute of Endocrinology approved the study, and all the patients and volunteers signed informed consent forms before participating in the study. 
Table 1. Comparison of anthropometric characteristics and indices of smoking in the sera of premenopausal female non-smokers and sex- and age-matched smokers (the data are shown as medians with quartiles in the parentheses).

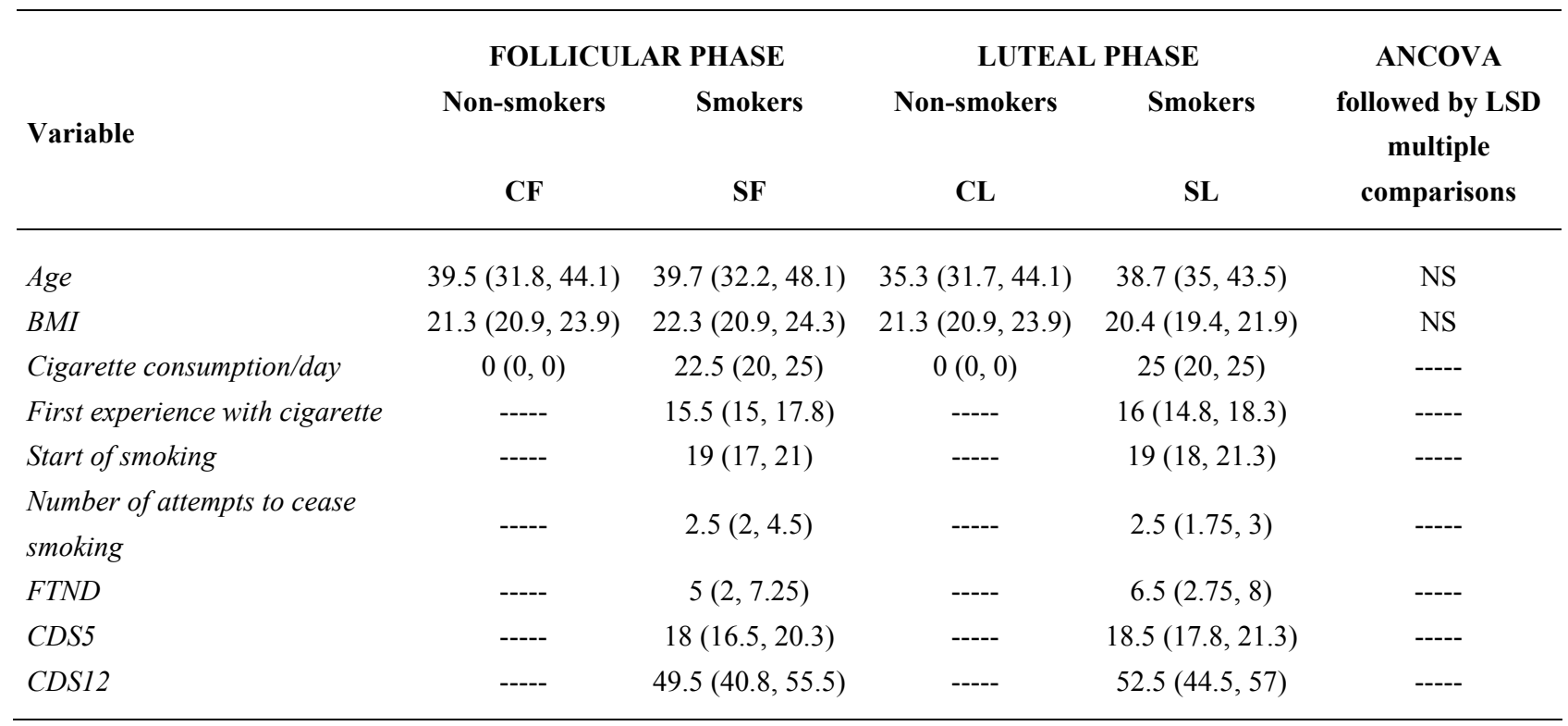

$\mathrm{NS}=$ not significant; $\mathrm{CF}=$ controls in the follicular phase; $\mathrm{CL}=$ controls in the luteal phase; $\mathrm{SF}=$ smokers in the follicular phase; $\mathrm{SL}=$ smokers in the luteal phase

\section{Steroids and chemicals}

Steroid standards were purchased from Steraloids (Wilton, NH, USA), and the solvents for the extraction and HPLC of an analytical grade were from Merck (Darmstadt, Germany). The derivatization agent Sylon BFT was from Supelco (Bellefonte, PA, USA) and the derivatization agent methoxylamine hydrochloride, as well as the remaining chemicals and solvents were from Sigma-Aldrich (St. Louis, MO, USA).

\section{Instruments}

The GC-MS system GCMS-QP2010 Plus was supplied by Shimadzu (Kyoto, Japan). The system consisted of a gas chromatograph equipped with automatic flow control, an AOC-20s auto-sampler, and a quadrupole electron-impact detector with an adjustable electron voltage of 10-195 V. A capillary column with a medium polarity RESTEK Rxi (diameter $0.25 \mathrm{~mm}$, length $15 \mathrm{~m}$, film thickness $0.1 \mu \mathrm{m}$ ) was used for the analyses.

\section{Steroid analysis}

Pregnenolone, conjugated pregnenolone, progesterone, $5 \alpha$-dihydroprogesterone, allopregnanolone, conjugated allopregnanolone, isopregnanolone, conjugated isopregnanolone, pregnanolone, conjugated pregnanolone, conjugated epipregnanolone, $20 \alpha$-dihydropregnenolone, conjugated 20a-dihydropregnenolone,

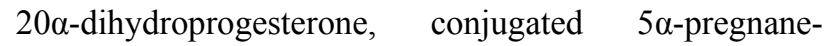

$3 \beta, 20 \alpha$-diol, conjugated $5 \beta$-pregnane- $3 \alpha, 20 \alpha$-diol, $16 \alpha$-hydroxy-pregnenolone, dehydroepiandrosterone, conjugated dehydroepiandrosterone, androstenediol, conjugated androstenediol, androstenedione, testosterone, $5 \alpha$-dihydrotestosterone, androsterone, conjugated androsterone, epiandrosterone, conjugated epiandrosterone, etiocholanolone, conjugated etiocholanolone, conjugated epietiocholanolone, conjugated $5 \alpha$-androstane- $3 \alpha, 17 \beta$-diol, conjugated $5 \alpha$-androstane$3 \beta, 17 \beta$-diol, $\quad 7 \alpha$-hydroxy-dehydroepiandrosterone, 7 $\beta$-hydroxy-dehydroepiandrosterone, 5-androstene$3 \beta, 7 \alpha, 17 \beta$-triol, and 5 -androstene-3 $\beta, 7 \beta, 17 \beta$-triol, measured using the GC-MS method that was published in detail elsewhere (Hill et al. 2009). The conjugated steroids were measured after hydrolysis according to Dehennin et al. (Dehennin et al. 1996).

Luteinizing hormone (LH) and follicle stimulating hormone (FSH) were estimated by IRMA kits from Immunotech (France). Sex hormone binding globulin (SHBG) and estradiol were assessed using IRMA kits from Orion (Finland). Cortisol was measured by the RIA kit from Orion (Finland). 17-hydroxyprogesterone was measured using the RIA kit from Immunotech (France). The immunoassays were processed on the automatic analyzer Stratec (France). Free and conjugated 17-hydroxypregnenolone was measured using our previously published methods (Hill et al. 1999, Vcelakova et al. 2007). The levels of free 
testosterone were calculated using the method reported elsewhere (Vermeulen et al. 1999).

\section{Statistical data analysis}

The ANOVA model consisting of smoking status (smokers vs. non-smokers), phase of the menstrual cycle (follicular- vs. luteal phase) as the main factors, and smoking status $\times$ phase of the menstrual cycle interaction was used for the simultaneous evaluation of the effects of smoking and phase of the menstrual. Least significant difference multiple comparisons (LSD) followed the ANCOVA testing.

Due to the complexity of our results, which exhibit strong correlations between individual variables; the ANOVA testing was followed by multivariate regression with the reduction of dimensionality (bidirectional orthogonal projections to a latent structure, OPLS).

The OPLS method enables the prediction of the variable average daily consumption of cigarettes constituting the vector $\mathbf{Y}$ from variables constituting the matrix $\mathbf{X}$. The predictivity of individual variables for the model may be simply expressed as a correlation of the variable with the common predictive component. The predictive component extracts the variability from $\mathbf{X}$, which is shared between $\mathbf{X}$ and $\mathbf{Y}$ from the variability within the $\mathbf{X}$, which is separated into the orthogonal components.

The OPLS method (Trygg et al. 2007, Trygg and Wold 2002) is effective in coping with the problem of severe multicollinearity within the matrix $\mathbf{X}$. The OPLS enabled us to detect the variables with high predictivity for the description of relationships between $\mathbf{X}$ and $\mathbf{Y}$. The OPLS model may be expressed as follows:

$$
\begin{aligned}
& \mathbf{X}=\mathbf{T}_{p} \mathbf{P}_{p}{ }^{t}+\mathbf{T}_{0} \mathbf{P}_{0}{ }^{t}+\mathbf{E} \\
& \mathbf{Y}=\mathbf{T}_{p} \mathbf{P}_{p}{ }^{t}+\mathbf{F}
\end{aligned}
$$

where $\mathbf{X}$ is the matrix with $l$ independent variables and $i$ subjects, $\mathbf{Y}$ is the vector of dependent variable and $i$ subjects. $\mathbf{T}_{\mathrm{p}}$ and $\mathbf{T}_{0}$ represent the matrices of the component scores from the predictive and orthogonal components, respectively extracted from $\mathbf{X} . \mathbf{P}_{\mathrm{p}}$ and $\mathbf{P}_{0}$ represent the matrices of component loadings from the predictive and orthogonal component, respectively extracted from $\mathbf{X}$. $\mathbf{E}$ and $\mathbf{F}$ are error terms.

We tested the relevance of individual variables for the model using a criterion Variable Importance (VIP).
Only the variables that showed significance for the relevant predictive components were included in the model.

Most of the data showed skewed data distribution and heteroscedasticity. To attain the Gaussian distribution and constant variance in the data and residuals, the original data were transformed by a power transformation for correct statistical testing. For each variable, we have used the parameter providing maximum agreement with the Gaussian distribution as evaluated using linear regression between theoretical percentiles of the Gaussian distribution and actual percentiles for individual transformed variables. The statistical software Statgraphics Centurion version XV from Statpoint Inc. (Herndon Virginia, USA) was used for simultaneous data transformation, ANOVA testing, and LSD multiple comparisons. The same software was used for the determination of optimal data transformations before the subsequent multivariate regression. The multivariate regression was accomplished using statistical software SIMCA-P+ Version 12.0.0.0 from Umetrics AB (Umeå, Sweden). This software also allowed for the detection of multivariate non-homogeneities using Hotelling's $T^{2}$ statistics and to check the multivariate normal distribution and homoscedasticity using the multivariate normal probability plot for residuals.

\section{Results}

The characteristics of smoking behavior for both groups of patients are illustrated in Table 1. We found no significant differences in age or BMI between the groups of study participants.

The concentrations of serum $\mathrm{LH}$, steroids, and steroid polar conjugates and SHBG exhibited significant differences between the smokers and non-smokers in the FP and/or LP (Tables 2 and 3). Smokers in both phases of the menstrual cycle showed higher levels of conjugated 17-hydroxypregnenolone, 5 $5 \alpha$-dihydroprogesterone,

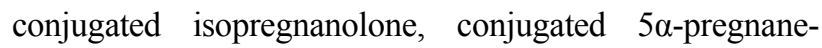
$3 \beta, 20 \alpha$-diol, conjugated androstenediol, androstenedione, testosterone, free testosterone, conjugated $5 \alpha$-androstane$3 \alpha / \beta, 17 \beta$-diols, and higher free testosterone index. In the FP, the smokers exhibited higher levels of conjugated pregnenolone, progesterone, conjugated pregnanolone, lutropin, and a higher lutropin/follitropin ratio, but lower levels of cortisol, allopregnanolone, and pregnanolone. In the LP, the smokers exhibited higher levels of free and conjugated $20 \alpha$-dihydropregnenolone, free and conjugated dehydroepiandrosterone, free androstenediol, $5 \alpha$-dihydrotestosterone, free and conjugated androsterone, 


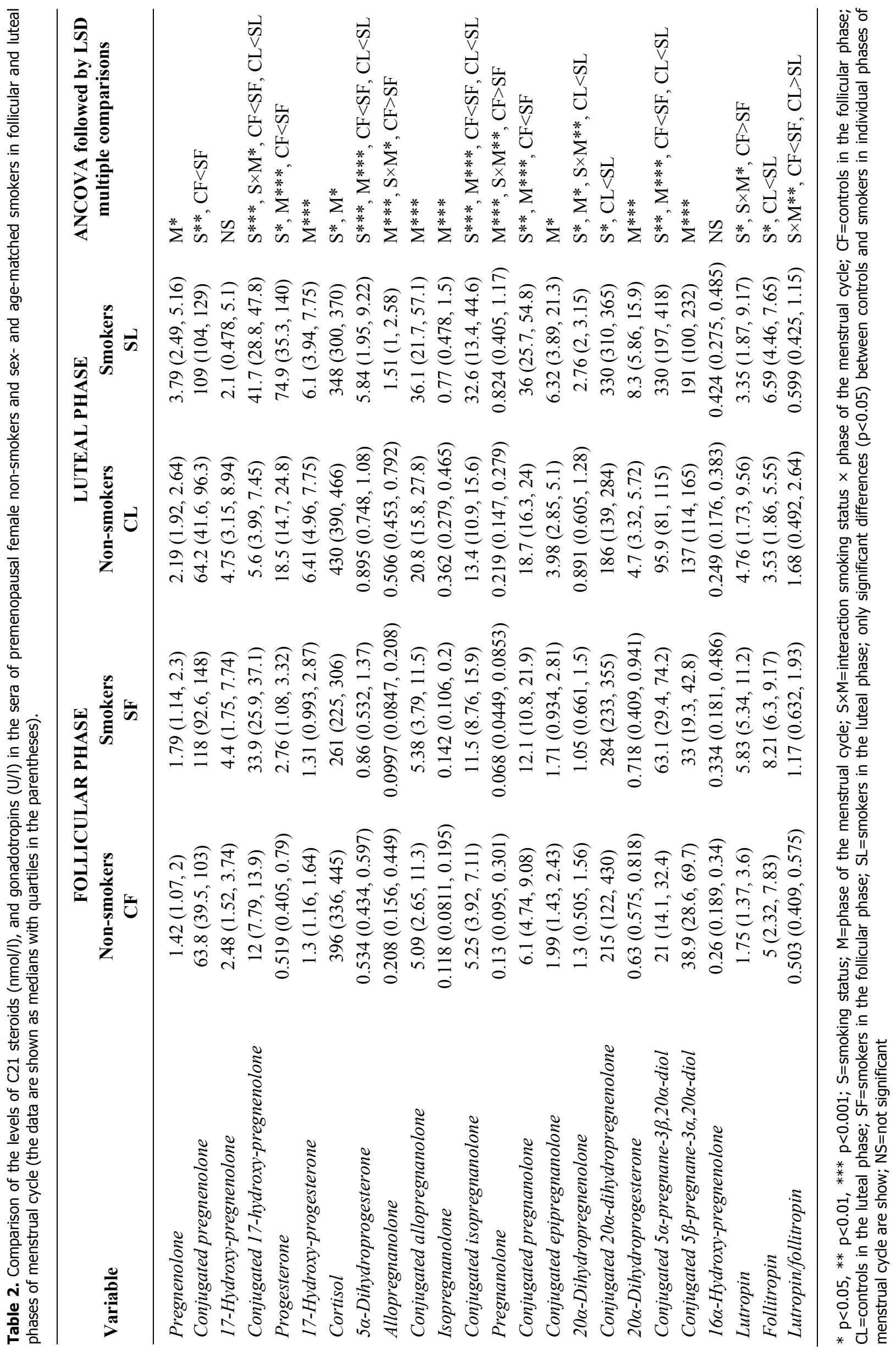




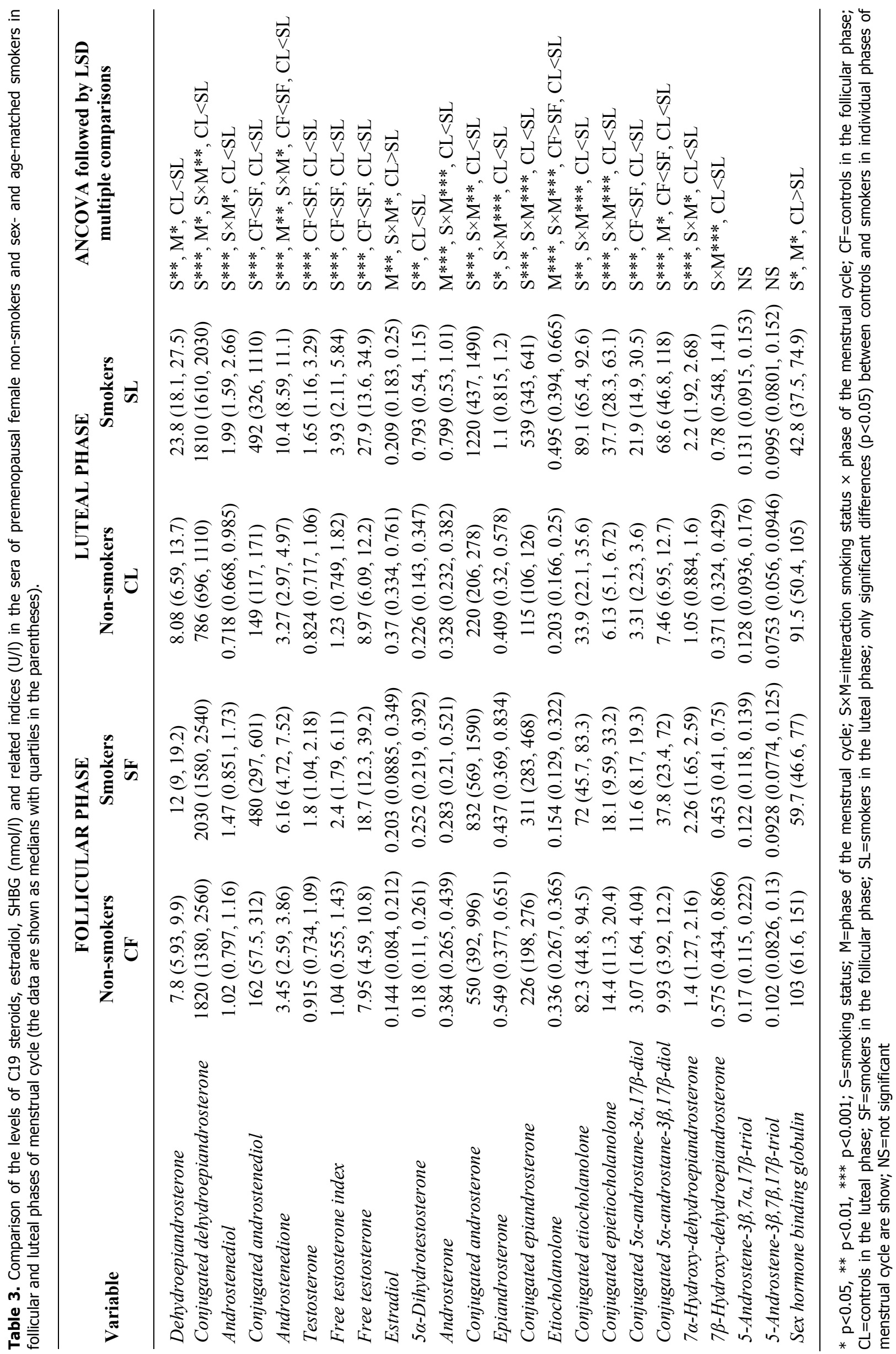


free and conjugated epiandrosterone, free and conjugated etiocholanolone, $\quad 7 \alpha / \beta$-hydroxy-dehydroepiandrosterone isomers, and follitropin but lower levels of estradiol and sex SHBG and lower values of the lutropin/follitropin ratio.

The OPLS model simultaneously evaluated the relationships between the average daily consumption of cigarettes representing vector $\mathbf{Y}$ and the levels of steroids and related substances constituting matrix $\mathbf{X}$. Using this approach, one predictive component was extracted. This predictive component separated the variability explaining the relationships between the average daily consumption of cigarettes and the levels of relevant analytes. To differentiate between the effects of the chronic smoking (expressed as the average daily consumption of cigarettes) in the FP and LP, the OPLS models were constructed separately for LP an FP. The results from the OPLS models generally agreed with the data from ANOVA.

Table 4. Relationships between chronic smoking (matrix $\mathbf{Y}$ ) and relevant serum steroids and related substances in the follicular phase of the menstrual cycle in women of fertile age (matrix $\mathbf{X}$ ) as simultaneously evaluated by multivariate regression with reduction of dimensionality using the method of orthogonal projections to latent structures (OPLS).

\begin{tabular}{|c|c|c|c|c|}
\hline \multicolumn{2}{|c|}{ Variable } & \multirow{2}{*}{ 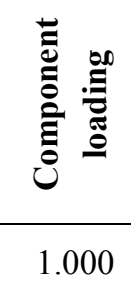 } & \multirow{2}{*}{ 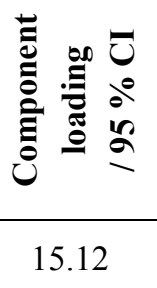 } & \multirow{2}{*}{$\begin{array}{c}\widetilde{\approx} \\
0.948 * *\end{array}$} \\
\hline $\boldsymbol{Y}$ & Cigarette consumption/day & & & \\
\hline \multirow{22}{*}{$X$} & Conjugated pregnenolone & 0.189 & 1.10 & $0.532 *$ \\
\hline & Conjugated 17-hydroxy-pregnenolone & 0.273 & 3.66 & $0.799 * *$ \\
\hline & Conjugated androstenediol & 0.252 & 3.95 & $0.707 * *$ \\
\hline & Progesterone & 0.209 & 1.38 & $0.588 *$ \\
\hline & Pregnanolone & -0.210 & -1.26 & $-0.590 *$ \\
\hline & Conjugated pregnanolone & 0.269 & 2.26 & $0.775 * *$ \\
\hline & Conjugated isopregnanolone & 0.234 & 2.14 & $0.673 * *$ \\
\hline & Conjugated $5 \alpha$-pregnane- $3 \beta, 20 \alpha$-diol & 0.112 & 0.99 & 0.314 \\
\hline & Conjugated $5 \beta$-pregnane- $3 \alpha, 20 \alpha$-diol & -0.131 & -1.16 & $-0.369 *$ \\
\hline & Androstenediol & 0.186 & 2.18 & $0.522 * *$ \\
\hline & Androstenedione & 0.243 & 1.76 & $0.682 * *$ \\
\hline & Testosterone & 0.186 & 1.41 & $0.522 *$ \\
\hline & Free testosterone index & 0.190 & 2.25 & $0.586 * *$ \\
\hline & Free testosterone & 0.190 & 2.20 & $0.586 * *$ \\
\hline & Conjugated epiandrosterone & 0.133 & 1.12 & $0.373 *$ \\
\hline & Etiocholanolone & -0.192 & -1.54 & $-0.549 *$ \\
\hline & Conjugated $5 \alpha$-androstane- $3 \alpha, 17 \beta$-diol & 0.264 & 3.48 & $0.741 * *$ \\
\hline & Conjugated $5 \alpha$-androstane- $3 \beta, 17 \beta$-diol & 0.281 & 5.91 & $0.789 * *$ \\
\hline & Lutropin & 0.298 & 3.38 & $0.835 * *$ \\
\hline & Follitropin & 0.143 & 1.22 & $0.429 *$ \\
\hline & Lutropin/follitropin & 0.227 & 1.42 & $0.608 *$ \\
\hline & Sex hormone binding globulin & -0.148 & -1.40 & $-0.462 *$ \\
\hline
\end{tabular}

\section{Variability explained by the predictive component}

$89.9 \%(80.5 \%$ after cross validation $)$

${ }^{a} \mathrm{R}=$ Component loading expressed as a correlation coefficient with the predictive component; $* \mathrm{p}<0.05, * * \mathrm{p}<0.01 ; \mathbf{X}=$ matrix $\mathbf{X}$; $\mathbf{Y}=$ vector $\mathbf{Y} ; \mathrm{CI}=$ confidence interval 
Table 5. Relationships between chronic smoking (matrix $\mathbf{Y}$ ) and relevant serum steroids and related substances in the luteal phase of the menstrual cycle in women of fertile age (matrix $\mathbf{X}$ ) as simultaneously evaluated by multivariate regression with reduction of dimensionality using the method of orthogonal projections to latent structures (OPLS).

\begin{tabular}{|c|c|c|c|c|}
\hline \multicolumn{2}{|c|}{ Variable } & \multirow{2}{*}{ 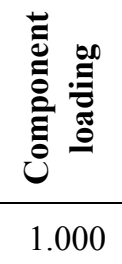 } & \multirow{2}{*}{ 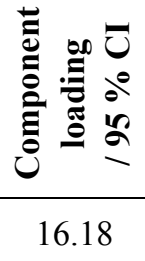 } & \multirow{2}{*}{$\begin{array}{l}\stackrel{\pi}{\simeq} \\
0.993 * *\end{array}$} \\
\hline $\boldsymbol{Y}$ & Cigarette consumption/day & & & \\
\hline \multirow{38}{*}{$X$} & Conjugated pregnenolone & 0.103 & 2.25 & $0.405 * *$ \\
\hline & Conjugated 17-hydroxy-pregnenolone & 0.203 & 2.63 & $0.822 * *$ \\
\hline & Progesterone & 0.149 & 1.71 & $0.607 * *$ \\
\hline & Cortisol & -0.141 & -1.84 & $-0.583 * *$ \\
\hline & $5 \alpha$-Dihydroprogesterone & 0.198 & 3.37 & $0.804 * *$ \\
\hline & Allopregnanolone & 0.176 & 1.93 & $0.714 * *$ \\
\hline & Isopregnanolone & 0.137 & 1.24 & $0.555 *$ \\
\hline & Conjugated isopregnanolone & 0.140 & 1.17 & $0.573 *$ \\
\hline & Pregnanolone & 0.169 & 2.45 & $0.687 * *$ \\
\hline & Conjugated pregnanolone & 0.140 & 1.17 & $0.567 *$ \\
\hline & 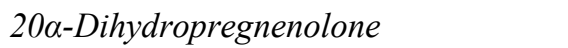 & 0.175 & 3.76 & $0.703 * *$ \\
\hline & 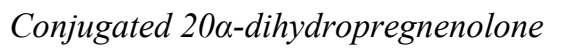 & 0.141 & 1.97 & $0.565 * *$ \\
\hline & 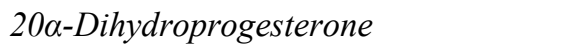 & 0.148 & 1.60 & $0.601 * *$ \\
\hline & Conjugated $5 \alpha$-pregnane- $3 \beta, 20 \alpha$-diol & 0.159 & 1.56 & $0.645 *$ \\
\hline & 16 $\alpha$-Hydroxy-pregnenolone & 0.093 & 1.12 & $0.369 *$ \\
\hline & Dehydroepiandrosterone & 0.148 & 2.94 & $0.593 * *$ \\
\hline & Conjugated dehydroepiandrosterone & 0.204 & 2.80 & $0.847 * *$ \\
\hline & Androstenediol & 0.164 & 4.03 & $0.657 * *$ \\
\hline & Conjugated androstenediol & 0.191 & 2.43 & $0.766 * *$ \\
\hline & Androstenedione & 0.150 & 2.37 & $0.603 * *$ \\
\hline & Testosterone & 0.135 & 1.67 & $0.541 * *$ \\
\hline & Free testosterone index & 0.153 & 1.54 & $0.614 *$ \\
\hline & Free testosterone & 0.154 & 1.65 & $0.616 * *$ \\
\hline & Estradiol & -0.170 & -2.03 & $-0.682 * *$ \\
\hline & $5 \alpha$-Dihydrotestosterone & 0.164 & 1.94 & $0.663 * *$ \\
\hline & Androsterone & 0.132 & 1.87 & $0.528 * *$ \\
\hline & Conjugated androsterone & 0.169 & 11.69 & $0.728 * *$ \\
\hline & Epiandrosterone & 0.147 & 2.46 & $0.590 * *$ \\
\hline & Conjugated epiandrosterone & 0.203 & 7.06 & $0.873 * *$ \\
\hline & Etiocholanolone & 0.150 & 2.91 & $0.604 * *$ \\
\hline & Conjugated etiocholanolone & 0.181 & 2.11 & $0.761 * *$ \\
\hline & Conjugated epietiocholanolone & 0.210 & 2.52 & $0.867 * *$ \\
\hline & Conjugated $5 \alpha$-androstane- $3 \alpha, 17 \beta$-diol & 0.207 & 3.36 & $0.882 * *$ \\
\hline & Conjugated $5 \alpha$-androstane- $3 \beta, 17 \beta$-diol & 0.197 & 4.15 & $0.882 * *$ \\
\hline & 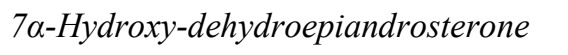 & 0.164 & 2.90 & $0.657 * *$ \\
\hline & 7 $\beta$-Hydroxy-dehydroepiandrosterone & 0.174 & 2.43 & $0.695 * *$ \\
\hline & 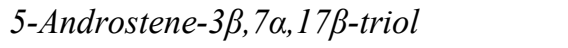 & 0.103 & 0.96 & 0.409 \\
\hline & Follitropin & 0.122 & 1.12 & $0.524 *$ \\
\hline
\end{tabular}


In the FP (Table 4), the average daily consumption of cigarettes positively correlated with conjugated pregnenolone, conjugated 17-hydroxypregnenolone, conjugated androstenediol, progesterone, conjugated pregnanolone, conjugated isopregnanolone, conjugated $5 \alpha$-pregnane-3 $\beta, 20 \alpha$-diol, androstenediol, androstenedione, testosterone, free testosterone index, free testosterone, conjugated epiandrosterone, conjugated $5 \alpha$-androstane- $3 \alpha, 17 \beta$-diol, conjugated $5 \alpha$-androstane$3 \beta, 17 \beta$-diol, lutropin, follitropin, and lutropin/follitropin ratio and negatively with pregnanolone, conjugated $5 \beta$-pregnane- $3 \alpha, 20 \alpha$-diol, etiocholanolone, and sex hormone binding globulin.

In the LP (Table 5), the average daily consumption of cigarettes positively correlated with conjugated pregnenolone, conjugated 17-hydroxypregnenolone, progesterone, 5 $\alpha$-dihydroprogesterone, allopregnanolone, isopregnanolone, conjugated isopregnanolone, pregnanolone, conjugated pregnanolone, 20 $\alpha$-dihydropregnenolone, conjugated $20 \alpha$-dihydropregnenolone, $\quad 20 \alpha$-dihydroprogesterone,

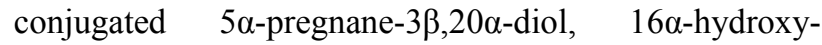
pregnenolone, dehydroepiandrosterone, conjugated dehydroepiandrosterone, androstenediol, conjugated androstenediol, androstenedione, testosterone, free testosterone index, free testosterone, 5 $\alpha$-dihydrotestosterone, androsterone, conjugated androsterone, epiandrosterone, conjugated epiandrosterone, etiocholanolone, conjugated etiocholanolone, conjugated epietiocholanolone, conjugated $5 \alpha$-androstane- $3 \alpha, 17 \beta$ diol, conjugated $5 \alpha$-androstane- $3 \beta, 17 \beta$-diol, $7 \alpha$-hydroxydehydroepiandrosterone, $7 \beta$-hydroxy-dehydroepiandrosterone, 5 -androstene-3 $\beta, 7 \alpha, 17 \beta$-triol, and follitropin but negatively with cortisol and estradiol.

\section{Discussion}

The present study is the first attempt to obtain a complex insight into the effects of chronic smoking on the steroid metabolome in premenopausal women. Some of the previous studies used a greater number of patients but were only focused on particular steroids. Concerning the steroid metabolites selected in the present study, besides for the common steroid hormones including their precursors and metabolites, we focused on the key metabolic steps, which are necessary for the synthesis of neuroactive and neuroprotective steroids. Although our study presents the most comprehensive analysis of serum steroid levels in female premenopausal smokers (both gonadal and adrenal) and it is the first study to look at both conjugated and unconjugated levels of steroids in these patients, due to technical reasons, the steroid inventory is still incomplete.

Most of other authors used immunoanalytical methods, which are inferior compared with GC-MS that was, for the most part, used in this study. On the other hand, the main limitation of this study is the relatively low number of subjects and consequently the low power of statistical testing. This means that there is a higher probability of falsely negative results, which may explain the small discrepancies between the results from multivariate regression and ANOVA.

The first outcome of this study is the finding that chronic cigarette smoking (compared with permanent tobacco abstinence) increases the levels of serum androgens, their $5 \alpha / \beta$-reduced metabolites (Tables 3, 4 and 5), and also the progestogen levels (progesterone, $5 \alpha$ DHP) (Tables 2, 4 and 5) but significantly suppresses serum estradiol in the LP (Tables 3 and 5). These results are partly in accordance with some older reports (Cauley et al. 1989, Friedman et al. 1987, Khaw et al. 1988, Longcope and Johnston 1988).

Our results demonstrate decreased cortisol levels regardless of the menstrual phase (Table 2). This data is consistent with the report from Back et al. (2008) showing that women smokers evidenced a more blunted cortisol response compared to non-smoking women.

Although some authors found no difference for the testosterone levels between female smokers and nonsmokers (Longcope and Johnston 1988), others observed increased levels of the steroid in premenopausal smokers (Friedman et al. 1987, Khaw et al. 1988, Sowers et al. 2001). Our data clearly demonstrate that premenopausal smokers have a tendency towards hyperandrogenism as documented by higher values of free testosterone index, elevated levels of total testosterone, free testosterone, and $5 \alpha$-dihydrotestosterone, as well as by pronouncedly elevated levels of $5 \alpha$-dihydrotestosterone metabolites, and conjugated $5 \alpha$-androstane- $3 \alpha / \beta, 17 \beta$-diols. Although multiple comparisons for SHBG levels show no differences between premenopausal smokers and nonsmokers in the FP, there is a difference in the LP and the effect of smoking in the ANCOVA model is significant, indicating consistently depressed SHBG regardless of the phase of the menstrual cycle (Table 3). This is consistent with elevated androgen levels. Estradiol levels in the LP are lower in the smokers. The aforesaid results are in agreement with a number of reports (Barbieri et al. 2005, 
Cupisti et al. 2010, Jensen et al. 1985, Manjer et al. 2005, Michnovicz et al. 1986, Sterzik et al. 1996, Van Voorhis et al. 1996), but are contradictory to others (Key et al. 1991, Khaw et al. 1988, Thomas et al. 1993).

The consistently increased concentration of free and conjugated $5 \alpha / \beta$-reduced androstane metabolites in LP and some of them in the FP (Table 3) may be a consequence of either augmented production rate of the precursors or a suppressed catabolism of the products. In contrast to our results, the measurements of metabolic clearance rate MCRs reported by Longcope and Johnson (Longcope and Johnston 1988) indicated that smoking does not alter the production and metabolism of androgens and estrogens in pre- and postmenopausal women. However, in the aforementioned study, those women who smoked had a lower BMI than non-smokers and their androgen and estrogen MCRs were lower, which probably resulted in higher plasma androgen concentrations (Longcope and Johnston 1988). In our study, smokers and non-smokers do not significantly differ in BMI.

Fertility problems in female smokers were established in many studies (Thomford and Mattison 1986, Freour et al. 2008). Increased levels of androgens could be one part of the problem.

Surprisingly, in contrast to the increased levels of progesterone and $5 \alpha$-DHP in both phases of MC, the levels of GABA-ergic pregnanolone isomers allopregnanolone and pregnanolone are suppressed in the FP (Table 2). On the other hand, conjugated isopregnanolone and conjugated pregnanolone levels are higher in smokers than in nonsmokers (Table 2), like most of the remaining steroid polar conjugates (Tables 2 and 3). This finding may indicate increased sulfotransferase activity in the patients than in the controls.

The well-being and health status in the women of reproductive age are generally associated with the phase of menstrual cycle and with the secretion of ovarian steroids. The results of Sufuoglu and colleagues who reported enhanced ratings of "bad effects," from nicotine and attenuation of the "drug liking" by progesterone indicate that neuroactive steroids might influence nicotine addiction (Sofuoglu et al. 2009). Neurocognitive functioning and mood in the LP may also be impaired due to changes in hypothalamic-pituitaryadrenal (HPA) axis function (Symonds et al. 2004). Our results show altered serum levels of various neuroactive and neuroprotective steroids (Tables 2-5). However, concerning the alterations in the serum levels of positive modulators of GABA-r, our results are not clear-cut.
While allopregnanolone, pregnanolone, and etiocholanolone in the FP are suppressed in the patients (Table 1), the etiocholanolone and androsterone levels in the LP are increased in these subjects (Table 2). On the other hand, the negative modulators of GABA-r and/or positive modulators of NMDA-r in the smokers show an unambiguously increasing trend as documented by the higher levels of conjugated pregnenolone (Table 2), conjugated DHEA (Table 3), and conjugated pregnanolone isomers (Table 2).

The premenstrual syndrome is found 2times more often in female smokers than in non-smokers PMS (Bertone-Johnson et al. 2008). Allopregnanolone correlates with the development of premenstrual syndrome (Bicikova et al. 1998). The decrease in serum allopregnanolone in the FP and alteration between phases could be one of the causes of higher incidence of premenstrual syndrome in female smokers.

In the present study, most of the biochemical measures were strongly correlated. When using ANCOVA followed by LSD multiple comparisons, there are too many differences that either limit the validity of the message or that can hardly be conceptualized. Therefore, besides for the ANCOVA model we have used the multivariate regression with the reduction of dimensionality. The OPLS model simultaneously evaluated the relationships between the average daily consumption of cigarettes (matrix $\mathbf{Y}$ ) and the strongly intercorrelated levels of steroids and related substances (matrix $\mathbf{X}$ ). Tables 2-5 demonstrate that the results from ANCOVA testing and multivariate regression were consistent, even if the multivariate model was slightly less sensitive, possibly due to the low number of study participants.

In conclusion, the first outcome of the present study is the finding that chronic cigarette smoking (compared with permanent tobacco abstinence) augments serum androgens including some $5 \alpha / \beta$-reduced androstane metabolites but suppresses estradiol levels in the LP, which may induce hyperandrogenism in the female smokers. The second outcome is the detection of increased serum progestogens but paradoxically suppressed levels of their GABA-ergic metabolites. The third outcome is the finding of lower cortisol in the patients supporting the concept of blunted cortisol response induced by chronic smoking as was recently suggested by Back et al. (2008). Although this study brings forth new data concerning the alterations in the steroid metabolome of chronic female smokers, further investigations are needed concerning these effects. In addition, the prospective changes or reinstatement of 
neuroactive and neuroprotective steroids in women of fertile age after the cessation of smoking require further investigation.

\section{Conflict of Interest}

There is no conflict of interest.

\section{Acknowledgements}

The excellent technical assistance of Ms. Vladěna Felbrová is gratefully acknowledged. The grant NS/10215-3 of the Internal Grant Agency of the Ministry of Health of the Czech Republic (IGA MZCR) and the grant SVV MSMT reg. c.262501 supported the study.

\section{References}

BACK SE, WALDROP AE, SALADIN ME, YEATTS SD, SIMPSON A, MCRAE AL, UPADHYAYA HP, CONTINI SISSON R, SPRATT EG, ALLEN J, KREEK MJ, BRADY KT: Effects of gender and cigarette smoking on reactivity to psychological and pharmacological stress provocation. Psychoneuroendocrinology 33: 560-568, 2008.

BARBIERI RL, SLUSS PM, POWERS RD, MCSHANE PM, VITONIS A, GINSBURG E, CRAMER DC: Association of body mass index, age, and cigarette smoking with serum testosterone levels in cycling women undergoing in vitro fertilization. Fertil Steril 83: 302-308, 2005.

BERTONE-JOHNSON ER, HANKINSON SE, JOHNSON SR, MANSON JE: Cigarette smoking and the development of premenstrual syndrome. Am J Epidemiol 168: 938-945, 2008.

BICIKOVA M, PUTZ Z, HILL M, HAMPL R, DIEBBELT L, TALLOVA J, STARKA L: Serum Levels of neurosteroid allopregnanolone in patients with premenstrual syndrome and patients after thyroidectomy. Endocr Regul 32: 87-92, 1998.

CAULEY JA, GUTAI JP, KULLER LH, LEDONNE D, POWELL JG: The epidemiology of serum sex hormones in postmenopausal women. Am J Epidemiol 129: 1120-1131, 1989.

CUPISTI S, HÄBERLE L, DITTRICH R, OPPELT PG, REISSMANN C, KRONAWITTER D, BECKMANN MW, MUELLER A: Smoking is associated with increased free testosterone and fasting insulin levels in women with polycystic ovary syndrome, resulting in aggravated insulin resistance. Fertil Steril 94: 673-677, 2010.

DEHENNIN L, LAFARGE P, DAILLY P, BAILLOUX D, LAFARGE JP: Combined profile of androgen glucuro- and sulfoconjugates in post-competition urine of sportsmen: a simple screening procedure using gas chromatography-mass spectrometry. J Chromatogr B Biomed Appl 687: 85-91, 1996.

DURAZZO TC, MEYERHOFF DJ: Neurobiological and neurocognitive effects of chronic cigarette smoking and alcoholism. Front Biosci 12: 4079-4100, 2007.

EPPERSON CN, O'MALLEY S, CZARKOWSKI KA, GUEORGUIEVA R, JATLOW P, SANACORA G, ROTHMAN DL, KRYSTAL JH, MASON GF: Sex, GABA, and nicotine: the impact of smoking on cortical GABA levels across the menstrual cycle as measured with proton magnetic resonance spectroscopy. Biol Psychiatry 57: 44-48, 2005.

FREOUR T, MASSON D, MIRALLIE S, JEAN M, BACH K, DEJOIE T, BARRIERE P: Active smoking compromises IVF outcome and affects ovarian reserve. Reprod Biomed Online 16: 96-102, 2008.

FRIEDMAN AJ, RAVNIKAR VA, BARBIERI RL: Serum steroid hormone profiles in postmenopausal smokers and nonsmokers. Fertil Steril 47: 398-401, 1987.

HILL M, HAMPL R, LUKAC D, LAPCIK O, POUZAR V, SULCOVA J: Elimination of cross-reactivity by addition of an excess of cross-reactant for radioimmunoassay of 17alpha-hydroxypregnenolone. Steroids 64: 341-355, 1999.

HILL M, PARIZEK A, KANCHEVA R, DUSKOVA M, VELIKOVA M, KRIZ L, KLIMKOVA M, PASKOVA A, ZIZKA Z, MATUCHA P, MELOUN M, STARKA L: Steroid metabolome in plasma from the umbilical artery, umbilical vein, maternal cubital vein and in amniotic fluid in normal and preterm labor. $J$ Steroid Biochem Mol Biol 2009.

HILL RD, NILSSON LG, NYBERG L, BACKMAN L: Cigarette smoking and cognitive performance in healthy Swedish adults. Age Ageing 32: 548-550, 2003. 
JENSEN J, CHRISTIANSEN C, RODBRO P: Cigarette smoking, serum estrogens, and bone loss during hormonereplacement therapy early after menopause. $N$ Engl J Med 313: 973-975, 1985.

KAPOOR D, JONES TH: Smoking and hormones in health and endocrine disorders. Eur J Endocrinol 152: 491-499, 2005.

KEY TJ, PIKE MC, BARON JA, MOORE JW, WANG DY, THOMAS BS, BULBROOK RD: Cigarette smoking and steroid hormones in women. J Steroid Biochem Mol Biol 39: 529-534, 1991.

KHAW KT, TAZUKE S, BARRETT-CONNOR E: Cigarette smoking and levels of adrenal androgens in postmenopausal women. $N$ Engl J Med 318: 1705-1709, 1988.

LONGCOPE C, JOHNSTON CC Jr: Androgen and estrogen dynamics in pre- and postmenopausal women: a comparison between smokers and nonsmokers. J Clin Endocrinol Metab 67: 379-383, 1988.

LUCERO J, HARLOW BL, BARBIERI RL, SLUSS P, CRAMER DW: Early follicular phase hormone levels in relation to patterns of alcohol, tobacco, and coffee use. Fertil Steril 76: 723-729, 2001.

MANJER J, JOHANSSON R, LENNER P: Smoking as a determinant for plasma levels of testosterone, androstenedione, and DHEAs in postmenopausal women. Eur J Epidemiol 20: 331-337, 2005.

MICHNOVICZ JJ, HERSHCOPF RJ, NAGANUMA H, BRADLOW HL, FISHMAN J: Increased 2-hydroxylation of estradiol as a possible mechanism for the anti-estrogenic effect of cigarette smoking. $N$ Engl J Med 315: 13051309, 1986.

MLYNARCIKOVA A, FICKOVA M, SCSUKOVA S: Ovarian intrafollicular processes as a target for cigarette smoke components and selected environmental reproductive disruptors. Endocr Regul 39: 21-32, 2005.

MUKHERJEE S, KONER BC, RAY S, RAY A: Environmental contaminants in pathogenesis of breast cancer. Indian $J$ Exp Biol 44: 597-617, 2006.

RICHARDS M, JARVIS MJ, THOMPSON N, WADSWORTH ME: Cigarette smoking and cognitive decline in midlife: evidence from a prospective birth cohort study. Am J Public Health 93: 994-998, 2003.

ROHLEDER N, KIRSCHBAUM C: The hypothalamic-pituitary-adrenal (HPA) axis in habitual smokers. Int $J$ Psychophysiol 59: 236-243, 2006.

SABIA S, MARMOT M, DUFOUIL C, SINGH-MANOUX A: Smoking history and cognitive function in middle age from the Whitehall II study. Arch Intern Med 168: 1165-1173, 2008.

SHIVERICK KT, SALAFIA C: Cigarette smoking and pregnancy I: ovarian, uterine and placental effects. Placenta 20: 265-272, 1999.

SOFUOGLU M, MITCHELL E, MOONEY M: Progesterone effects on subjective and physiological responses to intravenous nicotine in male and female smokers. Hum Psychopharmacol 24: 559-564, 2009.

SOFUOGLU M, POLING J, GONZALEZ G, GONSAI K, OLIVETO A, KOSTEN TR: Progesterone effects on cocaine use in male cocaine users maintained on methadone: a randomized, double-blind, pilot study. Exp Clin Psychopharmacol 15: 453-460, 2007.

SOWERS MF, BEEBE JL, MCCONNELL D, RANDOLPH J, JANNAUSCH M: Testosterone concentrations in women aged 25-50 years: associations with lifestyle, body composition, and ovarian status. Am J Epidemiol 153: 256-264, 2001.

STERZIK K, STREHLER E, DE SANTO M, TRUMPP N, ABT M, ROSENBUSCH B, SCHNEIDER A: Influence of smoking on fertility in women attending an in vitro fertilization program. Fertil Steril 65: 810-814, 1996.

SYMONDS CS, GALLAGHER P, THOMPSON JM, YOUNG AH: Effects of the menstrual cycle on mood, neurocognitive and neuroendocrine function in healthy premenopausal women. Psychol Med 34: 93-102, 2004.

THOMAS EJ, EDRIDGE W, WEDDELL A, MCGILL A, MCGARRIGLE HH: The impact of cigarette smoking on the plasma concentrations of gonadotrophins, ovarian steroids and androgens and upon the metabolism of oestrogens in the human female. Hum Reprod 8: 1187-1193, 1993.

THOMFORD PJ, MATTISON DR: The effect of cigarette smoking on female reproduction. J Ark Med Soc 82: 597604, 1986.

TRYGG J, HOLMES E, LUNDSTEDT T: Chemometrics in metabonomics. J Proteome Res 6: 469-479, 2007.

TRYGG J, WOLD S: Orthogonal projections to latent structure. J Chemometrics 16: 119-128, 2002.

TUTKA P: Nicotine and endocrine system in women. (in Polish) Pol Merkur Lekarski 10: 473-476, 2001.

TZIOMALOS K, CHARSOULIS F: Endocrine effects of tobacco smoking. Clin Endocrinol (Oxf) 61: 664-674, 2004. 
VAN VOORHIS BJ, DAWSON JD, STOVALL DW, SPARKS AE, SYROP CH: The effects of smoking on ovarian function and fertility during assisted reproduction cycles. Obstet Gynecol 88: 785-791, 1996.

VCELAKOVA H, HILL M, LAPCIK O, PARIZEK A: Determination of 17alpha-hydroxypregnenolone sulfate and its application in diagnostics. Steroids 72: 323-327, 2007.

VERMEULEN A, VERDONCK L, KAUFMAN JM: A critical evaluation of simple methods for the estimation of free testosterone in serum. J Clin Endocrinol Metab 84: 3666-3672, 1999.

WINDHAM GC, ELKIN EP, SWAN SH, WALLER KO, FENSTER L: Cigarette smoking and effects on menstrual function. Obstet Gynecol 93: 59-65, 1999.

WINDHAM GC, MITCHELL P, ANDERSON M, LASLEY BL: Cigarette smoking and effects on hormone function in premenopausal women. Environ Health Perspect 113: 1285-1290, 2005.

YOUNG DS: Implementation of SI units for clinical laboratory data. Style specifications and conversion tables. Ann Intern Med 106: 114-129, 1987.

ZUMOFF B, MILLER L, LEVIN J, LEVIT CD, MILLER EH, HEINZ U, KALIN M, DENMAN H, JANDOREK R, ROSENFELD RS: Follicular-phase serum progesterone levels of nonsmoking women do not differ from the levels of nonsmoking men. Steroids 55: 557-559, 1990. 